\title{
The effect of isolated imagery on free recall
}

\author{
HARLEY A. BERNBACH \\ Purdue University, West Lafayette, Ind. 47907 \\ and \\ PETER M. STALONAS \\ Cornell University, Ithaca, N.Y. 14850
}

Two groups of Ss learned lists of concrete nouns and were tested by free recall. An imagery group was instructed to form a separate, isolated image of each word as it was presented. The control group was given no special instructions except to learn the list. Performance by the control group was significantly better than that by the imagery group.

It would seem to be beyond dispute that, in some situations at least, instructed imagery is a powerful aid to memory (cf. Bower, 1970b, c). Even without imagery instructions, it has been found (e.g., Paivio, 1967) that nouns rated high on imagery and/or concreteness are remembered better in free recall than those rated low. Bower (1970c) suggests that the benefit from imagery comes about because imaging adds an additional code or engram to aid retrieval, and this dual-coding hypothesis is currently quite popular.

There exist some data that call the dual-coding hypothesis into question, however. Wood (1967) has reported no advantage in recall over a control group for Ss instructed to form a bizarre image of each response word in isolation. Wood concluded that the value of imagery is in helping to link items via a conglomerate image. Even Bower (1970a) has reported that noninteractive imagery of paired associates yielded recall not significantly different than that from rote repetition of the word pair. What, then, about the supposed additional engram?

It seemed that more direct information regarding the simple dual-coding hypothesis could be obtained by studying the effects of instructed separate mental imagery on a list of words in free recall. This was the purpose of the present study.

\section{METHOD}

\section{Materials}

Two pools of 234 words each were selected from the Paivio et al (1968) list of 925 words. These words were the 468 words rated highest for imagery (I) value. The two pools of words selected for this experiment were a high pool (mean I value 5.67, range 5.00-6.20) and a higher pool (mean I value 6.50, range 6.23-6.90). These two pools were then each divided into six lists of 13 words each and six lists of 26 words each. Each word was printed on a $3 \times 5$ in. index card.

\section{Subjects}

Two groups of 10 college students each comprised an imagery and a control group. Each group was further divided into a high-I and a higher-I list condition. Each of the four resulting groups contained three females and two males.

\section{Procedure}

Each list was presented at a rate of $5 \mathrm{sec}$ per word. After the presentation of a 13 -word list, Ss were given $1 \frac{1 / 2}{2}$ in to recall freely as many items as they could in an answer booklet. After the presentation of a 26 -word list, Ss were given 3 min for recall. The 12 lists were each presented once, with the 13- and 26-word lists alternated.

The control Ss were simply instructed to memorize the words. Ss in the imagery condition were told to: "Make a mental picture or image of each item in your mind. For example: if the first item is 'chair,' I would like you to picture in your mind a chair, create a visual, mental picture of a chair. If the next item were a 'hammer,' I would like you to picture a hammer. Before the presentation of each new word, I would like you to erase the picture of the previous item. Using my example, you would erase the picture of the chair before picturing the hammer. Two images should never appear in the same visualization. Some items will be easier and some more difficult to picture, but you must picture each item. Remember that it is important to make a specific, separate image of each item in your mind." The instructions were intentionally redundant to emphasize the desired strategy that was to be used. A pilot study had indicated that Ss tend to use conglomerate images unless instructions emphasize that separate images are desired.

\section{RESULTS}

The data were analyzed by a three-way analysis of variance. As there was no significant effect of I value in this study, either as main effect or in any interaction, the data are pooled across this factor in the following discussion. Performance in the control and imagery conditions for both list lengths is shown in Table 1. Performance is definitely better in the shorter lists $(p<.01)$, and it is worse in the imagery condition than in the control $(\mathrm{p}<.05)$. On the other hand, there is no sign of any interaction between these factors.

\section{DISCUSSION}

It seems clear from these results that isolated instructed imagery is not only of no help to free recall, but actually is a hindrance. Further, the dual-coding hypothesis is, at best, a gross oversimplification. The control Ss were free to process the lists according to their own cognitive styles, and they performed better for this. Questioning them revealed that most Ss used

Table 1

Proportion of Correct Responses as a Function of List Length and Experimental Condition

\begin{tabular}{lll}
\hline List Length & 13 & 26 \\
\hline Control & .74 & .53 \\
Imagery & .60 & .45 \\
\hline
\end{tabular}


some $\operatorname{kind}(\mathrm{s})$ of interactive processing strategies, i.e., grouping words, linking them in stories, and even sometimes creating conglomerate images.

In conclusion, we feel that too much emphasis has been placed on the supposed potency of innagery as an aid to recall. To be sure, interactive imagery is a powerful relational organizer in mnemonic systems using relations. However, in some situations at least, Ss are better off when allowed to choose their own processing strategies. Imagery appears to be one of many such possible strategies, and it is often an exceptionally useful one. It is not, however, magic.

\section{REFERENCES}

Bower, G. H. Imagery as a relational organizer in associative learning. Journal of Verbal Learning \& Verbal Behavior, 1970a, 9, 529-533.

Bower, G. H. Mental imagery and associative learning. In $L$. Gregg (Ed.), Cognition in learning and memory. New York: Wiley, $1970 \mathrm{~b}$.

Bower, G. H. Analysis of a mnemonic device. American Scientist, 1970c, 58, 496-510.

Paivio, A. Paired-associate learning and free recall of nouns as a function of concreteness, specificity, imagery, and meaningfulness. Psychological Reports, 1967, 20, 239-245.

Paivio, A., Yuille, J. C., \& Madigan, S. Concreteness, imagery and meaningfulness values for 925 nouns. Journal of Experimental Psychology, 1968, 76(1, Pt. 2).

Wood, G. Mnemonic systems in recall, Journal of Educational Psychology, 1967, 58(6, Pt. 2).

(Received for publication January 4, 1973.) 